\title{
Effect of Antiretroviral Drug (arved) on the Kidney in Albino Rat
}

\author{
*11PETERS, DE; UWAKWE, AA; MONAGO, CC \\ ${ }^{I}$ Department of Biochemistry, College of Natural and Applied Sciences, Faculty of Chemical Sciences, \\ University of Port Harcourt, Rivers State. Nigeria
} KEY WORDS: HIV, AIDs, Antiretroviral Drugs, Arved, Zidovudine, Lamivudine. Creatinine,
Urea, Potassium ion, Sodium ion, hypokalemia

\begin{abstract}
African studies on effect of antiretroviral drugs on the kidney are limited resulting to scanty information on the safety of these drugs. This study was therefore designed to evaluate the effects of antiretroviral drugs arved ${ }^{\circledR}$, on creatinine, urea, potassium and sodium ions as well as histological effect on the kidney. A total of fifty two (52) albino rats were randomly divided into four groups labeled A, B, C and D and kept in a well ventilated room. All experimental groups shared the same environmental conditions. Group A served as the control and rats were treated with distil water. Rats in groups B, C and D were, respectively treated with three different doses of arved $\left(1.07,3.21\right.$, and $\left.4.29 \mathrm{mg} \mathrm{kg}^{-1}\right)$. The drug was administered orally daily for 2, 4, 6, and 8 consecutive weeks. Animals were sacrificed twenty four hours after the last treatment. Blood samples were collected into heparinized sample bottles for biochemical analyses. The result of this study revealed a significant decrease $(p<0.05)$ in blood urea level in weeks 4 and 6 for treatment groups B and C when compared to control group. Mean creatinine values for all the treatment groups significantly increased $(\mathrm{p}<0.05)$ over the period of treatment when compared to the control value. Sodium ion showed a non significant increase $(\mathrm{p}>0.05)$ all through the period of treatment. Significant increase (of about 2 fold) $(p<0.05)$ of potassium ion was observed in all the treatment groups in weeks 6 and 8 of treatment. Histological examination of the kidney tissue of rats in group D treated with the drug for 8 weeks did not show any morphological change similar to that of the control group. In conclusion prolonged treatment of HIV/AIDS patients with arved could result to renal dysfunction. (C) JASEM
\end{abstract}

http://dx.doi.org/10.4314/jasem.v18 i2.27

Introduction: Highly active antiretroviral therapy (HAART) has revolutionized the management of HIV-AIDS and is effective in reducing morbidity and mortality in HIV-positive individuals. Several studies have shown dramatic improvements in the survival of HIV-infected patients treated with anti-retroviral therapy (ART) around the world including SubSaharan Africa (SSA) ( Weidle et al., 2002; Laurent et al., 2002). Kidney disorders are encountered at all stages of HIV infection, and they range from acute kidney injury (AKI) and divalent disorders commonly seen in hospitalized patients to chronic kidney disease (CKD) and end-stage renal disease (ESRD). Much has been written about HIVassociated nephropathy but as the disease evolves and people live longer, other causes of kidney diseases related to antiretroviral therapy and co-morbid conditions are becoming very important (Barsoum, 2006; Wild et al., 2006). HAART and other medical therapies for HIV-associated infections have been associated with both short and long term toxicities including nephrotoxicity. HIV-associated nephropathy (HIVAN), the most usual form of HIV-1 related nephropathy, consist of mostly of glomerular nephropathies, but also of vascular or tubulointerstitial nephropathies (Weiner et al., 2003). HIVAN may be the consequence of HIV-1 replication in the kidney. HIVAN usually affects black patients and is known to be a leading cause of end- stage renal disease (ESRD) in this population in North America and in Europe. The marked racial predisposition of HIV-associated nephropathy (HIVAN) to blacks has been previously reported (D' Agati et al., 1998) recent studies have confirmed this association. Analysis of data from United States Renal Data System revealed that HIVAN is more strongly associated with black race than any other cause of failure with the exception of sickle cell disease. (Abbott et al., 2001) Hailemarian et al., 2001 reported a series of 239 autopsies performed on patients with AIDS in Switzerland from 1981 to 1989 (before introduction of HAART). Various abnormalities were reported among the 228 white patients. However, the only case of HIVAN in these autopsies was detected in one of the six African patients involved in the study. This marked racial 
disparity in HIVAN suggests that genetic factors are important determinants of HIVAN pathogenesis. Since the onset of HAART, national epidemiologic data showed the reduction of incidence of ESRD due to HIVAN in the United States (Weiner et al., 2003). This suggests that antiretroviral therapy may prevent HIVAN or at least slow it course. Preliminary retrospective series or case reports support the efficacy of HAART in improving outcome in HIVAN (Kirchner, 2002; Cosgrove et al.,2002; Saulsbury, 2001). There are over 20 drugs for HIV treatment on the market but the availability and choices of drug combinations are limited in subSaharan Africa (SSA). The commonly prescribed HAART regimens vary from country to country (Cantor et al., 1991; Ross \& Klotman, 2002). However, the most commonly prescribed initial regimens include Nucleos(t)ide reverse transcriptase inhibitors (NRTIs) and non-reverse transcriptase inhibitors (NNRTIs). Nucleoside and nucleotide reverse transcriptase inhibitors inhibit the viral reverse transcriptase and halt viral DNA synthesis. The commonly prescribed NRTIs include zidovudine (AZT), lamivudine (3TC), stavudine (D4T), emtricitabine (FTC), abacavir (ABC), didanosine (DDI) and zalcitabine (DDC). The only nucleotide analog currently used is tenofovir (TDF), which is commonly used in combination with FTC as Truvada ${ }^{\circledR}$. Arved $®$ is a brand name for the domestically produced zidovudine-lamivudine preparation of anti-retroviral drug called Combivir. It is a fixed dose combination of two antiretroviral drugs, lamivudine (also called 3TC, with the brand name Epivir) and zidovudine (also called AZT, with the brand name retriovir). Both lamivudine and zidovudine are reverse transcriptase inhibitors which block the action of an enzyme, reverse transcriptase that the virus required for reproduction. It reduces the viral load in the body and raise $\mathrm{CD} 4^{+}$cell count. It was approved for use in the United States by the Food and Drug Administration (FDA) on September 26, 1997, making it the thirteenth approved antiretroviral. All NRTIs except abacavir are primarily excreted by the kidney and require dose adjustments based on creatinine clearance. Lamivudine, stavudine, abacavir and didanosine have been implicated in case reports of Fanconi syndrome and nephrogenic diabetes insipidus (Ahmad, 2006; Nelson et al., 2008; D'Ythurbide et al., 2007). Abacavir causes acute interstitial nephritis as part of the hypersensitivity reaction. The nucleotide analog tenofovir is actively taken up into the proximal tubules and secreted into the lumen via multi-drug resistance-associated protein (Ray et al., 2006). A number of observational studies have documented tenofovir-associated nephrotoxicity following its widespread use in patients with multiple co-morbid conditions. Tenofovir induced renal toxicity is more likely to occur in HIV patients with pre-existing renal insufficiency or poorly controlled HIV disease with longer overall antiviral treatment duration. Complications of tenofovir, alone or in combination with other antivirals, include AKI, nephrogenic diabetes insipidus, Fanconi syndrome, and severe hypokalemia ( Coca and Perazella, 2002; Izzedine et al., 2004; Zimmermann et al., 2006, Gupta, 2008). Most of these adverse reactions can be reversed with discontinuation of the drug, although some will develop CKD. The growing population of patients treated with HAART and the predicted larger use of these regimens in patients with previous HIV- or non- HIV related nephropathies require the consideration of the potential renal side-effects of antiretroviral treatments. There is paucity of data on the HAART-associated renal disease status in Nigeria despite the fact that Nigeria remains the country with the third highest number of HIV-infected subjects in the world (WHO/UNAIDS 2009), therefore this study was aimed at evaluating the effect of antiretroviral therapy on kidney function using animal model.

\section{MATERIALS AND METHODS}

Antiretroviral Drug Sample: Antiretroviral drug sample named arved used in this study was purchased from NAFDAC approved pharmaceutical store located opposite the gate of University of Port Harcourt Teaching Hospital, Alakahia, Rivers State of Nigeria. The details of the drug are stated below;

1.ARVED ${ }^{\circledR} \quad$-SNP 30,Active Ingredients (Zidovudine:300mg and Lamivudine: $150 \mathrm{mg}$ ) Manufactured by Cipla LTD., Plot No L-139 Verna,Goa 403722, India. For: Evans Medical PLC, Km. 32 Lagos Expressway, Lagos State. Batch. No: G973223

Specimen (Animal) Used For The Experiment: Fifty two (52) albino rats were purchased from the Department of Human Physiology, University of Nigeria Enugu Campus (UNEC) and acclimatized for one week at the Animal House of Biochemistry Department, University of Port Harcourt located at the botanical garden Choba Park. During acclimatization, the animals were fed with rat pellets and water ad libitum.

Chemicals And Reagents: All chemicals and reagents used in this study were of analytical grade.

Equipment. Centrifuge (Universal 320, Hettich Zentrifugen Germany), refrigerator( Frestech ), 
colorimeter ( Jenway 6051 colorimeter; UK), weighing balance (Mettle Toledo. AB 204, Switzerland), Spectrophotometer (Beckman Coulter, DU 520 General Purpose UV / Visual), water bath (UNISCOPE-Sn801Asurgifriend medicals, England). Ion Selective Electrode (ISE) Humalyte machine (Human, Germany).

Preparation Of Drug Solution For Administration: One tablet of the drug- arved was ground to a fine powder and dissolved in $100 \mathrm{ml}$ of distilled water to make a therapeutic dose concentration of $(4.29 \mathrm{mg} / \mathrm{kgBW})$ which served as group D drug treatment. Two other concentrations were prepared by adding $7.5 \mathrm{ml}$ and $2.5 \mathrm{ml}$ of distil water to $2.5 \mathrm{ml}$ and $7.5 \mathrm{ml}$ respectively of the therapeutic dose concentration to make dose concentrations of 3.21 and $1.07 \mathrm{mg} / \mathrm{kgBW}$ for groups $\mathrm{C}$ and $\mathrm{B}$ treatments.

Experimental Procedure : A total of fifty two albino rats (52) of weight range $(150-175 \mathrm{gBW})$ were randomly divided into four groups labelled A, B, C and D. Group A served as control and rats(n=4rats/dose) were treated with distilled water. Rats in groups $\mathrm{D}, \mathrm{C}$ and $\mathrm{B}(\mathrm{n}=4 \mathrm{rats} / \mathrm{dose})$ were orally treated with three different doses of arved $(4.29,3.21$, $1.07 \mathrm{mg} / \mathrm{kgBW}$ ), daily for $2,4,6$ and 8 weeks. Animals were sacrificed twenty four (24) hours after the last treatment.

Drug administration to rats: $0.25 \mathrm{ml}$ of the drug solution was administered at the different concentrations to the animal in the groups using syringe. Administration was done orally twice daily.

Collection Of Blood And Preparation Of Serum: The rats were withdrawn from the cages in each of the group twenty four (24) hours after the last administration of drugs for 2,4,6 and 8 weeks and placed in a desiccator containing cotton wool soaked in chloroform to anaesthetize the rats. The blood samples were obtained by cutting the jugular vein of the rat on the neck by means of surgical blade and put in anticoagulant sample bottles smeared with lithiumheparin. The blood samples were spun at 5000rpm using MSE centrifuge to obtain serum. Rats were dissected and the liver was collected.

Biochemical parameters estimation for kidney function.: Serum urea was determined by urease enzymatic method, creatinine by Jaffe's reaction and. Serum sodium and potassium levels were determined by ion selective electrode method using Humalyte machine (Human, Germany) (Tietz 1987).

\section{Histopathological examination}

A small portion of the kidney tissues from groups A and D were excised immediately after sacrifice. Tissues were fixed in $10 \%$ formalin in phosphate buffer $(\mathrm{pH} \mathrm{7.0)}$ ) for $24 \mathrm{hr}$ at room temperature for histopathology. Tissues were embedded in paraffin was and sections were cut 3-5 $\square \mathrm{m}$ slices and were stained with haematoxylin and eosin (H\&E) and observed under light microscope (Galigher et al., 1971).

Statistical Analysis: Results were analyzed using (SPSS) version 15. The data were expressed using descriptive statistics and Analysis Of Variance (ANOVA). Multiple comparisons for the groups were done using Post Hoc Turkey (HSD) to test for the level of significance between means. A $p<0.05$ was considered to be statistically significant. Values are expressed in Means \pm Standard Deviation $(\mathrm{M} \pm \mathrm{SD})$. Superscript a: Indicates significant difference $(\mathrm{p}<0.05)$

\section{RESULT AND DISCUSSION}

Table 1 Effect of oral administration of antiretroviral drug(arved) on urea(mmol/L) level of albino rats for 8 weeks

\begin{tabular}{lllll}
\hline & Week2 & Week4 & Weeks of Administration & Week6 \\
Drug treatment/Control groups & & & M \pm SD & \\
Group A (Control) & & & $5.00 \pm 0.45$ & \\
Group B $(1.07 \mathrm{mg} / \mathrm{KgBW})$ & $4.60 \pm 0.52$ & $3.38 \pm 0.48^{\mathrm{a}}$ & $3.27 \pm 0.61^{\mathrm{a}}$ & $5.15 \pm 0.90$ \\
Group C $(3.21 \mathrm{mg} / \mathrm{KgBW})$ & $5.00 \pm 0.77$ & $3.50 \pm 0.61$ & $2.90 \pm 0.12^{\mathrm{a}}$ & $5.80 \pm 0.37$ \\
Group D(4.29mg/KgBW) & $4.60 \pm 0.39$ & $3.33 \pm 0.47^{\mathrm{a}}$ & $3.50 \pm 0.41$ & $5.23 \pm 0.68$ \\
\hline
\end{tabular}

Result is represented in mean \pm standard deviation $(\mathrm{M} \pm \mathrm{SD})$

Superscript ' $a$ ' represents significant difference when compared to control value

\begin{tabular}{lcccc}
\hline \multicolumn{4}{c}{ Table 2 Effect of oral administration of antiretroviral drug(arved) on creatinine(mmol/L) level of albino rats for 8 weeks } \\
\hline & Week2 & Week4 & Weeks of Administration \\
& & & Week6 & Week8 \\
Drug treatment/Control groups & & & $39.00 \pm 2.58$ & \\
Group A (Control) & $49.25 \pm 2.22^{\mathrm{a}}$ & $52.00 \pm 6.73^{\mathrm{a}}$ & $41.00 \pm 2.16$ & $59.75 \pm 1.71^{\mathrm{a}}$ \\
Group B(1.07mg/KgBW) & $49.00 \pm 2.16^{\mathrm{a}}$ & $47.25 \pm 6.60$ & $45.50 \pm 2.89$ & $54.67 \pm 2.36^{\mathrm{a}}$ \\
Group C $(3.21 \mathrm{mg} / \mathrm{KgBW})$ & $53.75 \pm 2.63^{\mathrm{a}}$ & $47.33 \pm 2.49$ & $52.00 \pm 2.45^{\mathrm{a}}$ & $55.50 \pm 3.42^{\mathrm{a}}$ \\
Group D(4.29mg/KgBW) &
\end{tabular}

\footnotetext{
*I PETERS, DE; UWAKWE, AA; MONAGO, CC
} 
Result is represented in mean \pm standard deviation $(\mathrm{M} \pm \mathrm{SD})$

Superscript 'a' represents significant difference when compared to control value

\begin{tabular}{lcccc}
\hline Table 3 Effect of oral administration of antiretroviral drug(arved) on sodium ion (mmol/L) level of albino \\
& \multicolumn{3}{c}{ rats for 8 weeks } & Weeks of Administration \\
& Week2 & Week4 & Week6 & Week8 \\
& & & M \pm SD & \\
Drug treatment/Control groups & & & $137.00 \pm 6.16$ & \\
Group A (Control) & $143.75 \pm 5.74$ & $139.50 \pm 3.70$ & $141.33 \pm 0.41$ & $145.75 \pm 2.22$ \\
Group B $(1.07 \mathrm{mg} / \mathrm{KgBW})$ & $137.50 \pm 4.20$ & $136.00 \pm 7.39$ & $144.25 \pm 2.22$ & $146.67 \pm 1.70$ \\
Group C $(3.21 \mathrm{mg} / \mathrm{KgBW})$ & $143.25 \pm 5.44$ & $142.00 \pm 0.82$ & $139.67 \pm 1.25$ & $145.25 \pm 2.22$ \\
Group D $(4.29 \mathrm{mg} / \mathrm{KgBW})$ & &
\end{tabular}

Result is represented in mean \pm standard deviation $(\mathrm{M} \pm \mathrm{SD})$

\begin{tabular}{lcccc}
\hline \multicolumn{2}{c}{ Table 4 Effect of oral administration of antiretroviral drug(arved) on potassium ion (mmol/L) level of albino } \\
& \multicolumn{3}{c}{ rats for 8 weeks } \\
& Week2 & Week4 & $\begin{array}{c}\text { Weeks of Administration } \\
\text { Week6 }\end{array}$ & Week8 \\
& & & M $\pm \mathrm{SD}$ & \\
Drug treatment/Control groups & & & $10.08 \pm 0.31$ & \\
Group A (Control) & $7.63 \pm 1.33$ & $5.53 \pm 0.76^{\mathrm{a}}$ & $5.73 \pm 0.52^{\mathrm{a}}$ & $5.60 \pm 0.36^{\mathrm{a}}$ \\
Group B $(1.07 \mathrm{mg} / \mathrm{KgBW})$ & $8.20 \pm 0.82$ & $6.30 \pm 0.72$ & $5.00 \pm 0.73^{\mathrm{a}}$ & $5.03 \pm 0.74^{\mathrm{a}}$ \\
Group C $(3.21 \mathrm{mg} / \mathrm{KgBW})$ & $8.40 \pm 0.88$ & $6.20 \pm 0.51$ & $5.43 \pm 0.31^{\mathrm{a}}$ & $5.50 \pm 0.18^{\mathrm{a}}$ \\
Group D(4.29mg/KgBW) &
\end{tabular}

Result is represented in mean \pm standard deviation $(\mathrm{M} \pm \mathrm{SD})$

Superscript ' $a$ ' represents significant difference when compared to control value

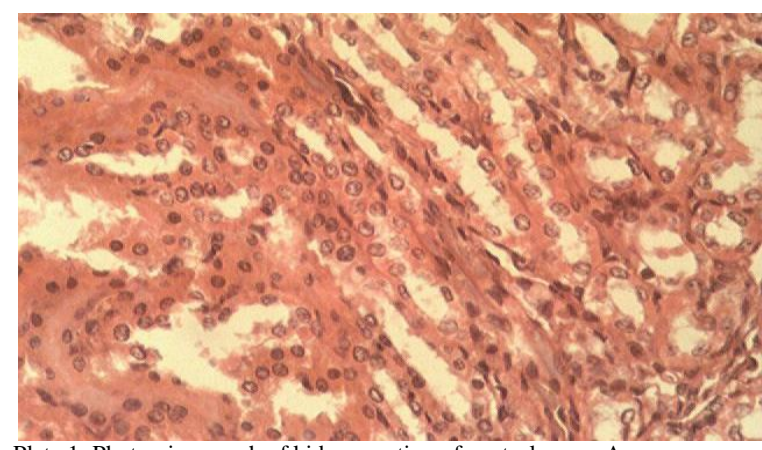

Plate 1 :Photomicrograph of kidney section of control group A (treated with distil water) showed normal architecture with normal glomeruli, tubules, interstitium and blood vessels (H\&Ex400)

The result of this study from Table 1 demonstrated a significant decrease $(\mathrm{p}<0.05)$ in blood urea level in weeks 4 for treatment groups $\mathrm{B}$ and $\mathrm{C}$ $(3.38 \pm 0.48 ; 3.33 \pm 0.47 \mathrm{mmol} / \mathrm{l}$ respectively) and week 6 for treatment groups B and C (3.27 \pm 0.61 ; $2.90 \pm 0.12 \mathrm{mmol} / \mathrm{l}$ respectively) when compared to the control value. Mean creatinine levels for all the treatment groups significantly increased $(\mathrm{p}<0.05)$ over the period of treatment when compared to the control value as shown in Table 2. Sodium ion in Table 3 showed a non significant increase $(p>0.05)$ all through the period of treatment. In Table 4, significant increase (of about 2 fold) $(\mathrm{p}<0.05)$ of potassium ion was observed in all the treatment groups in weeks 6 and 8 of treatment. Histology of the kidney tissue did not show any morphological change in group D week 8 treatment when compared to the control group.

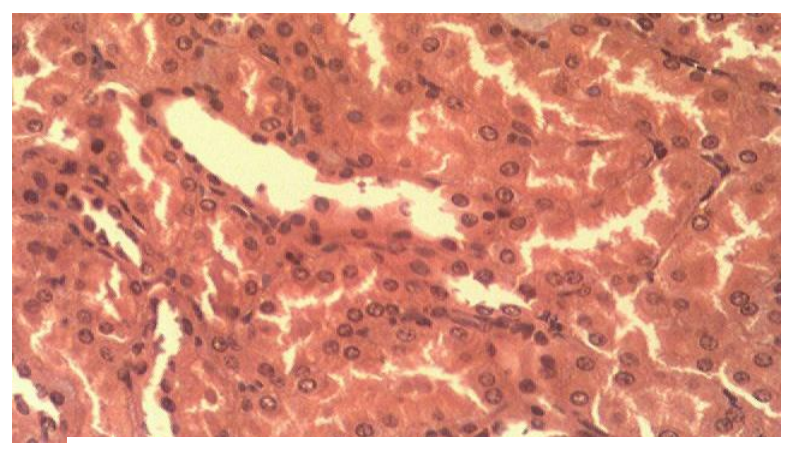

Plate 2 :Photomicrograph of Kidney section treated $4.29 \mathrm{mg} / \mathrm{kgBW}$ of arved for weeks 8 (group D) showing normal architecture with normal glomeruli, tubules, interstitium and blood vessels (H\&E x400)

The changes observed in these parameters indicate impairment in the functions of the kidney. Electrolyte disturbances are common in AIDS patients (Wyatt and Winston, 2006). Marked changes in electrolyte balance can result from the many and varied drugs used to control AIDS infection or can be secondary to opportunistic infections. Antiretroviral drug use can cause renal failure through a variety of mechanisms: direct renal tubular toxicity (ATN, Fanconi-like syndrome, distal tubular acidosis, etc.), obstructions (crystal deposition in the kidney), and glomerular lesions (Izzedine et al., 2005 and Daugas et al., 2005). It has been shown that hypokalemia constitutes a risk factor for the development of acute kidney injury (AKI) (Seguro et al.,1989 and Menahem et al., 1999). It is also known that hypokalemia enhances the tubular damage resulting from ischemic injury (Menahem et al., 1999). The antiretroviral drugs zidovudine (AZT) and didanosine 
(ddI) are widely used in AIDS patients, and data suggest that their use in patients with hypokalemia can have adverse effects on renal function (Seguro et al., 2003). It has been shown that both drugs decrease glomerular filtration rate and renal blood flow in hypokalemic rats, but that only AZT reduces glomerular filtration rate and renal blood flow in rats with hypomagnesemia. Therefore, chronic AZT and ddI administration can produce AKI in AIDS patients with hypokalemia or hypomagnesemia (Seguro et al.,2003). Lamivudine, stavudine, abacavir and didanosine have been implicated in case reports of fanconi syndrome and nephrogenic diabetes insipidus (Ahmad, 2006; D'YThurbide et al., 2007 and Nelson et al, 2008). Some studies have discovered that nucleoside reverse transcriptase inhibitor induced renal toxicity may involve the proximal tubule similar to nucleotide RTI. One case implicated didanosine (Crowther et al., 1993) while another implicated lamivudine and/ or stavudine (Morris et al., 2001). Others research works have also shown, acute renal failure in patient with lactic acidosis secondary to nucleoside RTI-related acquired mitochonfdrial cythopathy (Kakuda et al., 2000; Tanji et al., 2001 and Murohy et al., 2003).However, urea level (Table 1) showed significant decrease in weeks 4 and 6 treatment with arved treatment. Studies done by Fromenty et al. (1995) and Brinkman et al. (1998) ascribed adverse effects of nucleoside analogs mainly to impairment of mitochondrial DNA (mtDNA) replication, causing mtDNA depletion, impaired oxidative phosphorylation and ATP deficiency. Coghlan et al. (2001) and de Mendoza et al. (2004) in their research observed that the spectrum of mitochondrial toxicity of NRTI drugs ranges from nonspecific symptoms to lactic acidosis syndrome with fulminant hepatic failure. The decrease in urea levels observed in this work in arved treatment groups can therefore be attributed to impairment of urea synthesis in the liver due to mitochondrial toxicity associated with NRTIs since the rate determining step in urea cycle takes place in the mitochondrial. However, histopathological observation of kidney tissue showed normal kidney architecture for group D treated with the highest dose of arved for 8 weeks.

Therefore in conclusion prolonged treatment of HIV/AIDS patients with arved could result to renal impairment.

\section{REFERENCES}

Abbott, K.C.E., Hypolite, I., Welch, P.G \& Agodoa, L.Y. (2001) Human Immunodeficiency Virus/acquired immunodeficiency syndrome-associated nephropathy at end-stage renal diseases in the united States: patient characteristics and survival in the pre highly active anti retroviral therapy era. J. Nephrol. 14: 277-383,

Ahmad, M. (2006). Abacavir-induced reversible Fanconi syndrome with nephrogenic diabetes insipidus in a patient with acquired immunodeficiency syndrome. Journal of Postgraduade Medicine 52:296-297.

Barsoum, R.S. (2006). Chronic kidney disease in the developing world. N. Engl. J. Med. 354:997-999.

Brinkman, K., ter Hofstede, H., Burger, D., Smeitink, J. \& Koopmans, P. (1998). Adverse effects of reverse transcriptase inhibitors: Mitochondrial toxicity as common pathway. AIDS 12:1735-1744.

Cantor, E.S., Kimmel, P.L. \& Bosch J.P. (1991). Effect of race on expression of acquired immunodeficiency syndrome-associated nephropathy.Arch. Intern. Med. 151:125-128

Coca, S. \& Perazella, M.A. (2002). Rapid communication: acute renal failure associated with tenofovir: evidence of drug-induced nephrotoxicity. Am. J. Med. Sci. 324:342-344.

Coghlan, M., Sommadossi, J., Jhala, N., Many, W., Saag, M. \& Johnson, V. (2001). Symptomatic lacticacidosis in hospitalized antiretroviral-treated patients with HIV infection: a report of 12 cases. Clinical Infectious. Disease 33:1914-1921.

Cosgrove, C.J., Abu-Alex, A.K. \& Perzella, M.A.(2002). Observation on acquired immunodeficiency syndrome-associated renal disease in the era of HAART. Am. J. Med. Sci. 323:102-107

Crowther, M.A., Calllaghan, W. \& Hodsman, A.B. (1993). Dideoxyinosine-associated nephrotoxicity AIDS 7:131-132

D’ Agati, V., Suh, J.I., Carbone, L., (1998). Pathology of HIV-associated nephropathy: A detailed morphologic and comparative study. Kidney Int. 35: 1358-1370

Daugas, E., Rougier, J.P. \& Hill, G. (2005). HAARTrelated nephropathies in HIV-infected patients. Kidney International 67: 393-403.

de Mendoza, C., de Ronde, A., Smolders, K., Blanco, F., Garcia-Benayas, T. \& de Baar, M. (2004). Changes in mitochondrial DNA copy number in blood cells from HIV-infected patients undergoing antiretroviral therapy. AIDS Research in Human Retroviruses. 20:271-273

D'Ythurbide, G., Goujard, C., Mechai, F., Blanc, A., Charpentier, B. \& Snanoudj, R. (2007). Fanconi syndrome and nephrogenic diabetes insipidus associated with didanosine therapy in HIV infection: A case report and literature review. Nephrol. Dial. Transplant. 22:3656-3659. 
Fromenty, B. \& Pessayre, D. (1997). Impaired mitochondrial function in microvesicular steatosis. Effects of drugs, ethanol, hormones and cytokines. Journal of Hepatology 26(suppl 2):43-53.

Galigher et al. 1971. Essentials of Practical Microtechnique, 2nd Ed. Lea and Febiger, Philadelphia. pp -77 .

Hailemarian, S., Walder, M., Burger, H.R., Cathomas, G., MIhatsch, M., Binswanger, U.\& Ambuhl, P,M (2001).Renal Pathology and premortem clinical presentation of Caucasian patients with AIDS: An autopsy study from the era prior to antiretroviral therapy. Swiss Med. Weekly 131; 412-417

Gupta, S.K (2008). Tenofovir-associated Fanconi syndrome: review of the FDA adverse event reporting system. AIDS Patient Care STDS 22:99-103.

Izzedine, H., Launay-Vacher, V. \& Deray, G. (2005). Antiviral drug-induced nephrotoxicity. American Journal of Kidney Disease 45: 804-817.

Izzedine, H., Isnard-Bagnis, C., Hulot, J.S., Vittecoq, D., Cheng, A., Jais, C.K., Launay-Vacher, V. \& Deray, G. (2004). Renal safety of tenofovir in HIV treatment-experienced patients. Aids 18:1074-1076.

Kakuda, T.N. (2000). Phamacology of nucleoside and nonnucleoside reverse transcriptase inhibitor-induced mitochondrial toxicity. Clinical Therapeutics 22:685-708

Keiser, O., Anastos, K., Schechter, M., Balestre, E., Myer, L., Boulle, A., Bangsberg, D., Toure, H., Braitstein, P. \& Sprinz, E.(2008). Antiretroviral therapy in resource-limited settings 1996 to 2006: patient characteristics, treatment regimens and monitoring in sub-Saharan Africa, Asia and Latin America. Trop. Med. Int. Health 13:870-879.

Kirchner, J.I. (2002). Resolution of renal failure after initiation of HAART 3 cases discussion of the literature.AIDS. 12:103105

Larmarange, J. (2009). [HIV prevalence in sub-Saharan Africa: background of an estimation]. Med. Sci. (Paris) 25:87-92.

Laurent, C., Diakhate, N., Gueye, N.F., Toure, M.A., Sow, P.S., Faye, M.A., Gueye, M., Laniece, I., Toure, K. C. \& Liegeois, F. (2002). The Senegalese government's highly active antiretroviral therapy initiative: an 18-month follow-up study. AIDS 16:1363-1370.

Menahem, S.A., Perry, G.J., Dowling, J. \& Thomson, N.M. (1999) Hypokalaemia-induced acute renal failure. Nephrol. Dial. Transplant. 14: 2216-2218.

Morris, A.A., Baudouin, S.V. \& Snow, M.H.(2001). Renal tubular acidosis and hypophosphatamia after treatment with nucleoside reverse transcriptase inhibitor. Aids 15:140-141.

Murphy, M.D., O'Hearn, M. \& Chou, S. (2003). Fatal lactic acidosis and acute renal failure after addition of tenotovir to an antiretroviral regimen containing didanosine Clinical Infectious Disease 36:1082-1085.
Nelson, M., Azwa, A., Sokwala, A., Harania, R.S. \& Stebbing, J.(2008). Fanconi syndrome and lactic acidosis associated with stavudine and lamivudine therapy. Aids 22:1374-1376.

Ray, A.S., Cihlar, T., Robinson. K.L., Tong, L., Vela, J.E., Fuller, M.D., Wieman, L.M., Eisenberg, E,J. \& Rhodes, G.R (2006). Mechanism of active renal tubular efflux of tenofovir. Antimicrob. Agents Chemother. 50:3297-3304.

Ross, M.J \& Klotman, P.E. (2002). Recent progress in acquired immunodeficiency syndrome-associated nephropathy. J. Am. Soc. Nephrol. 13:2997-3004.

Saulsbury, F. (2001). Resolution of organ-specific complication of acquired immunodeficiency syndrome infection in children with use of HAART. Clin. Infect. Dis. 32:464-468

Seguro, A.C., de Araujo, M., Seguro, F.S., Rienzo, M., Magaldi, A.J. \& Campos, S.B. (2003). Effects of hypokalemia and hypomagnesemia on zidovudine (AZT) and didanosine (ddI) nephrotoxicity in rats. Clinical Nephrology 59: 267-272.

Seguro, A.C., Shimizu, M.H., Monteiro, J.L. \& Rocha, A.S. (1989). Effect of potassium depletion on ischemic renal failure. Nephron 51: 350-354.

Tanji, N., Tanji, K. \& Kambhan, N. (2001). Adefovir nephrotoxicity:Possible role of mitochondrial DNA depletion. Human Pathology 32:734-740.

Tietz, N.W., (1987). Fundamentals of clinical chemistry. 3rd Ed. W.B. Saunders, Philadelphia, pp: 470-560.

Weidle, P.J., Malamba, S., Mwebaze, R., Sozi, C., Rukundo, G., Downing, R., Hanson, D., Ochola, D., Mugyenyi, P. \& Mermin, J. (2002) Assessment of a pilot antiretroviral drug therapy programme in Uganda: patients' response, survival, and drug resistance. Lancet 360:34-40.

Weiner, N.J., Goodman, J.W., \& Kimmel, P.L.(2003). The HIVassociated renal disease: current insight into pathogenesis and treatment. Kidney Int. 63:1618-1631.

WHO/UNAIDS, (2009). Global summary of the HIV/AIDS epidemic. December 2009. www.unaids.org.

Wild, S., Roglic, G., Green, A., Sicree, R. \& King, H. (2004). Global prevalence of diabetes: estimates for the year 2000 and projections for 2030. Diabetes Care 27:1047-1053.

Wyatt, C.M. \& Winston, J. (2006). Renal disease in patients with HIV. Current Infectious Disease Report 8: 76-81.

Zimmermann, A.E., Pizzoferrato, T., Bedford, J., Morris, A., Hoffman, R. \& Braden, G (2006). Tenofovir-associated acute and chronic kidney disease: a case of multiple drug interactions. Clin. Infect. Dis. 42:283-290. 